\title{
Are we ready to withdraw acetylsalicylic acid after complex percutaneous coronary intervention?
}

\author{
Gabriella Bufano ${ }^{1,2}$, Marco Zimarino ${ }^{1,3}$ \\ ${ }^{1}$ Institute of Cardiology, “G. d'Annunzio” University, Chieti, Italy \\ ${ }^{2}$ Department of Medical, Oral and Biotechnological Sciences, University “Gabriele d'Annunzio”, Chieti, Italy \\ ${ }^{3}$ Cath Lab, Ospedale SS. Annunziata, ASL 2 Abruzzo, Chieti, Italy
}

This editorial
accompanies
the article on
page 855

Dual antiplatelet therapy (DAPT) with acetylsalicylic acid (ASA) and a $\mathrm{P}_{2} \mathrm{Y}_{12}$ receptor inhibitor is the cornerstone treatment both in patients with acute coronary syndromes

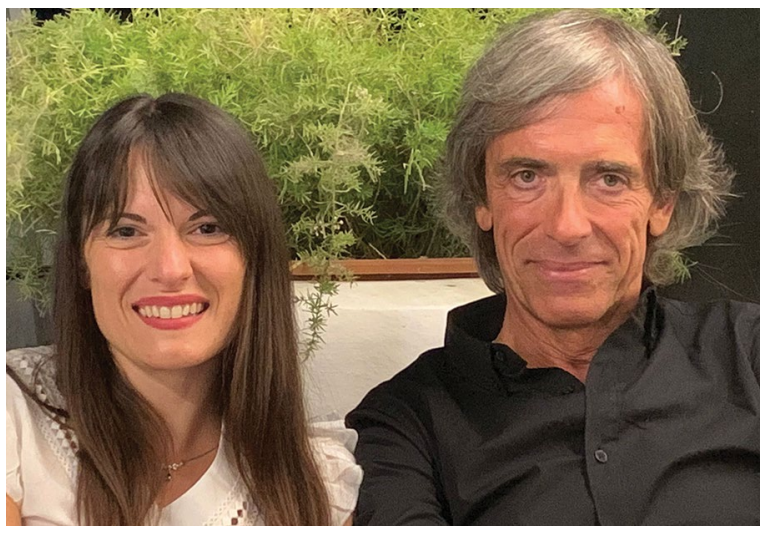

(ACS) and in those undergoing percutaneous coronary intervention (PCI). At the beginning of the drug-eluting stent (DES) era, stent thrombosis (ST) emerged as the most relevant complication, and therefore more powerful $\mathrm{P}_{2} \mathrm{Y}_{12}$ inhibition and DAPT prolongation were recommended $[1,2]$.

With technological refinements, newer thinner-strut DES now show dramatically improved safety profiles compared with their ancestors [3]. The increased safety of third generation DES has encouraged the treatment of complex lesions in older and more fragile patients, in whom the bleeding risk still carries relevant prognostic implications [4].

For the definition of the complex PCI, we commonly refer to the so-called "Giustino's criteria" [5]: either 3 vessel or $\geq 3$ lesions treated, $\geq 3$ stents implanted, bifurcation with 2 stents, total stent length $>60 \mathrm{~mm}$ or treatment of a chronic total occlusion, with most of the ischemic risk driv- planned strategy [7].

en by double bifurcation stenting. In the setting of bifurcation PCI, a single "provisional" stenting is currently recommended by the European Bifurcation Club (EBC) consensus document [6], but careful planning is mandatory, as the ischemic risk is heightened when the second stent is placed in "bail-out", beyond the

In addition, the identification of high bleeding risk (HBR) patients $[8,9]$ has become crucial to define the DAPT strategy [10]. In HBR patients, the overlap between ischemic and bleeding features is common and therefore the evaluation of the net clinical benefit of DAPT duration becomes tricky. Costa et al. [11] documented that those patients enrolled in the PRECISE-DAPT study who underwent complex PCI had a higher risk of ischemic events, but benefitted from long-term DAPT only if HBR features were not present. In order to obtain an optimal balancing between the ischemic and the thrombotic risk, a modulation of antithrombotic strategy has been proposed, with an initial DAPT period to reduce the ST risk during the phase of strut endothelialization, followed by long-term antiplatelet monotherapy with either ASA or a $\mathrm{P} 2 \mathrm{Y}_{12}$ receptor inhibitor to contain the bleeding risk [12]. In the subgroup of patients with complex lesions

Address for correspondence: Marco Zimarino, MD, PhD, Cath Lab and Institute of Cardiology, ASL2 Abruzzo and “G. d’Annunzio" University of Chieti, c/o Ospedale SS. Annunziata, Via dei Vestini, 66100 Chieti, Italy, tel: +39-0871-41512, fax: +39-0871-402817, e-mail: m.zimarino@unich.it

Received: 17.08.2021 Accepted: 20.08.2021

This article is available in open access under Creative Common Attribution-Non-Commercial-No Derivatives 4.0 International (CC BY-NC-ND 4.0) license, allowing to download articles and share them with others as long as they credit the authors and the publisher, but without permission to change them in any way or use them commercially. 


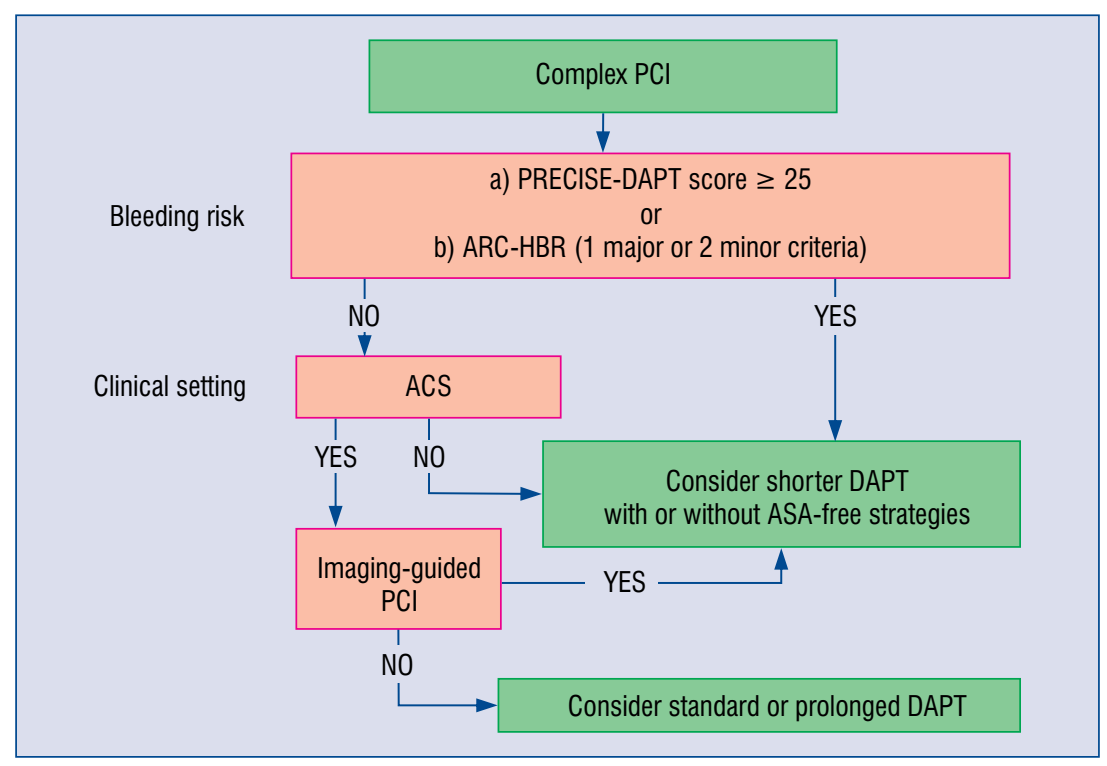

Figure 1. Decisional algorithm proposed for antiplatelet duration after complex percutaneous coronary intervention (PCI); ACS - acute coronary syndrome; ARC — Academic Research Consortium; ASA — acetylsalicylic acid; HBR — high-bleeding risk; DAPT — dual antiplatelet therapy; PRECISE-DAPT — PREdicting bleeding Complications in patients undergoing stent Implantation and SubsequEnt Dual AntiPlatelet Therapy. Bleeding risk stratification according to PRECISE-DAPT score and ARC-HBR score is defined as a 1-year risk of a BARC (bleeding ARC) type 3 or $5 \geq 4 \%$ or of intracranial hemorrhage $\geq 1 \%$.

enrolled in the TWILIGHT trial, Dangas et al. [13] showed that, after 3-month DAPT, continuation of ticagrelor monotherapy was associated with a lower incidence of bleeding without increasing the risk of ischemic events compared with continuing DAPT.

The multicentric, randomized, open-label SMART-CHOICE trial [14] enrolled 2,993 patients - with ACS in $60 \%$ of cases - undergoing PCI with second generation DES in Korea to receive 12-month DAPT vs. 3-month DAPT followed by P2Y 12 monotherapy (mostly clopidogrel). At 12 months of follow-up, shorter DAPT followed by P2Y 12 monotherapy was non-inferior to 12 -month DAPT for the primary endpoint of major adverse cardiac and cerebrovascular events, with a lower rate of bleeding events expressed as Bleeding Academic Research Consortium (BARC) bleeding type 2-5. In the current issue of the Cardiology Journal, Roh et al. [15] performed a post-hoc analysis of the SMART-CHOICE trial among the 498 patients who underwent complex PCI, with intravascular ultrasound guidance used in $31.5 \%$ of cases. Similary to the TWILIGHT trial, also in the SMART-CHOICE complex, the $\mathrm{P}_{2} \mathrm{Y}_{12}$ inhibitor monotherapy showed adverse event rates comparable to the DAPT group.
Two recent meta-analyses [16, 17] showed that shorter DAPT regimens followed by $\mathrm{P}_{2} \mathrm{Y}_{12}$ monotherapy appear safe in containing bleeding events, without a significant increase in ischemic risk among unselected patients.

Looking ahead, complex PCI undoubtedly deserves careful planning, with single stenting recommended in bifurcations, and when double stenting is needed, imaging becomes vital to optimize strut overlapping and reduce the risk of strut malapposition. In this view, the EBC proposed a modulated DAPT duration strategy according to clinical presentation, HBR, stenting strategy and the use of intraprocedural imaging [18].

At present, the optimal DAPT duration after complex PCI is still under debate. ASA-free strategies, in light of the limited evidence, cannot be routinely recommended and should be restricted to selected patients. A meaningful approach should take into account both clinical and procedural risk variables (Fig. 1).

In the nearest future, without doubt we will witness several trials focusing various de-escalation antiplatelet therapeutic approaches after PCI or ACS [19].

Conflict of interest: None declared 


\section{References}

1. Valgimigli M, Bueno H, Byrne RA, et al. 2017 ESC focused update on dual antiplatelet therapy in coronary artery disease developed in collaboration with EACTS: The Task Force for dual antiplatelet therapy in coronary artery disease of the European Society of Cardiology (ESC) and of the European Association for Cardio-Thoracic Surgery (EACTS). Eur Heart J. 2018; 39(3): 213-260, doi: 10.1093/eurheartj/ehx419, indexed in Pubmed: 28886622.

2. Zimarino M, Renda G, De Caterina R. Optimal duration of antiplatelet therapy in recipients of coronary drug-eluting stents. Drugs. 2005; 65(6): 725-732, doi: 10.2165/00003495-20056506000001, indexed in Pubmed: 15819586.

3. Serruys PW, Farooq V, Kalesan B, et al. Improved safety and reduction in stent thrombosis associated with biodegradable polymer-based biolimus-eluting stents versus durable polymer-based sirolimus-eluting stents in patients with coronary artery disease: final 5-year report of the LEADERS (Limus Eluted From A Durable Versus ERodable Stent Coating) randomized, noninferiority trial. JACC Cardiovasc Interv. 2013; 6(8): 777-789, doi: 10.1016/j.jcin.2013.04.011, indexed in Pubmed: 23968698.

4. Eikelboom JW, Mehta SR, Anand SS, et al. Adverse impact of bleeding on prognosis in patients with acute coronary syndromes. Circulation. 2006; 114(8): 774-782, doi: 10.1161/CIRCULATIONAHA.106.612812, indexed in Pubmed: 16908769.

5. Giustino G, Chieffo A, Palmerini T, et al. Efficacy and safety of dual antiplatelet therapy after complex PCI. J Am Coll Cardiol. 2016; 68(17): 1851-1864, doi: 10.1016/j.jacc.2016.07.760, indexed in Pubmed: 27595509.

6. Burzotta F, Lassen JF, Lefèvre T, et al. Percutaneous coronary intervention for bifurcation coronary lesions: the 15 consensus document from the European Bifurcation Club. EuroIntervention. 2021; 16(16): 1307-1317, doi: 10.4244/EIJ-D-20-00169, indexed in Pubmed: 33074152.

7. Zimarino M, Briguori C, Amat-Santos IJ, et al. Mid-term outcomes after percutaneous interventions in coronary bifurcations. Int J Cardiol. 2019; 283: 78-83, doi: 10.1016/j.ijcard.2018.11.139, indexed in Pubmed: 30528620.

8. Costa F, Klaveren Dv, James S, et al. Derivation and validation of the predicting bleeding complications in patients undergoing stent implantation and subsequent dual antiplatelet therapy (PRECISE-DAPT) score: a pooled analysis of individual-patient datasets from clinical trials. Lancet. 2017; 389(10073): 1025-1034, doi: 10.1016/s0140-6736(17)30397-5.

9. Urban P, Mehran R, Colleran R, et al. Defining high bleeding risk in patients undergoing percutaneous coronary intervention: a consensus document from the Academic Research Consortium for High Bleeding Risk. Eur Heart J. 2019; 40(31): 2632-2653, doi: 10.1093/eurheartj/ehz372, indexed in Pubmed: 31116395.

10. Collet JP, Thiele H, Barbato E, et al. 2020 ESC Guidelines for the management of acute coronary syndromes in patients presenting without persistent ST-segment elevation. Eur Heart J. 2021; 42(14): 1289-1367, doi: 10.1093/eurheartj/ehaa575, indexed in Pubmed: 32860058.

11. Costa F, Van Klaveren D, Feres F, et al. Dual antiplatelet therapy duration based on ischemic and bleeding risks after coronary stenting. J Am Coll Cardiol. 2019; 73(7): 741-754, doi: 10.1016/j.jacc.2018.11.048, indexed in Pubmed: 30784667.

12. Capodanno D, Mehran R, Valgimigli M, et al. Aspirin-free strategies in cardiovascular disease and cardioembolic stroke prevention. Nat Rev Cardiol. 2018; 15(8): 480-496, doi: 10.1038/s41569018-0049-1, indexed in Pubmed: 29973709.

13. Dangas G, Baber U, Sharma S, et al. Ticagrelor with or without aspirin after complex pci. J Am Coll Cardiol. 2020; 75(19): 2414-2424, doi: 10.1016/j.jacc.2020.03.011, indexed in Pubmed: 32240761.

14. Hahn JY, Song YB, Oh JH, et al. Effect of P2Y12 Inhibitor Monotherapy vs Dual Antiplatelet Therapy on Cardiovascular Events in Patients Undergoing Percutaneous Coronary Intervention: The SMARTCHOICE Randomized Clinical Trial. JAMA. 2019; 321(24): 2428-2437, doi: 10.1001/jama.2019.8146, indexed in Pubmed: 31237645.

15. Roh JW, Hahn JY, Oh JH, et al. $\mathrm{P}_{12} \mathrm{Y}_{12}$ inhibitor monotherapy in complex percutaneous coronary intervention: A post-hoc analysis of SMART-CHOICE randomized clinical trial. Cardiol J. 2021; 28(6): 855-863, doi: 10.5603/CJ.a2021.0101.

16. O'Donoghue ML, Murphy SA, Sabatine MS. The Safety and Efficacy of Aspirin Discontinuation on a Background of a P2Y Inhibitor in Patients After Percutaneous Coronary Intervention: A Systematic Review and Meta-Analysis. Circulation. 2020; 142(6): 538-545, doi: 10.1161/CIRCULATIONAHA.120.046251, indexed in Pubmed: 32551860.

17. Giacoppo D, Matsuda Y, Fovino LN, et al. Short dual antiplatelet therapy followed by P2Y12 inhibitor monotherapy vs. prolonged dual antiplatelet therapy after percutaneous coronary intervention with second-generation drug-eluting stents: a systematic review and metaanalysis of randomized clinical trials. Eur Heart J. 2021; 42(4): 308-319, doi: 10.1093/eurheartj/ehaa739, indexed in Pubmed: 33284979.

18. Zimarino M, Angiolillo DJ, Dangas G, et al. Antithrombotic therapy after percutaneous coronary intervention of bifurcation lesions. EuroIntervention. 2021; 17(1): 59-66, doi: 10.4244/EIJD-20-00885, indexed in Pubmed: 32928716.

19. Kubica J, Adamski P, Niezgoda P, et al. A new approach to ticagrelor-based de-escalation of antiplatelet therapy after acute coronary syndrome. A rationale for a randomized, double-blind, placebo-controlled, investigator-initiated, multicenter clinical study. Cardiol J. 2021; 28(4): 607-614, doi: 10.5603/CJ.a2021.0056, indexed in Pubmed: 34096012. 